\title{
Integrating Technology in Teacher Education Curriculum and Pedagogical Practices: the Effects of Web-based Technology Resources on Pre-service Teachers' Achievement in Teacher Education Training
}

\author{
Sani Alhaji Garba, Termit Kaur Ranjit Singh and Najeemah Mohammed Yusuf \\ School of Educational Studies, Universiti Sains Malaysia \\ Penang, Malaysia \\ sanialhajigarba@yahoo.com
}

\begin{abstract}
Teachers' ICT literacy skills and competence is a crucial factor that determines the success and sustainability of integrating the use of web-based technology resources in educational practices. Thus, ensuring effective technology integration in teacher education is accorded a deserving attention in most countries. However, meaningful technology integration in teacher education would require on one hand 'the integration of technology in teacher education curriculum'; and, 'the integration of technology in teacher education pedagogical practices' on the other hand in addition to the need for teacher educators to model the use of technology in their practices. This study examines the effects of integrating web-based technology resources in teacher education pedagogical practices using the inquiry approach in line with the GPM model; and the effects of technology (web-based technology resources) in social studies teacher education curriculum in line with the TPACK theory. Three (3) groups quasi-experimental design involving $\mathbf{4 5}$ pre-service teachers was employed for the study. The study therefore investigate and compare the effect of three different interventions (ICT Integration) involving the use of Standard technology; web-resources and power point; and, web-based resources and smart board for groups 1, 2, and three respectively. The participants were selected from four colleges of education. One way ANOVA was used for data analysis. Finding from the study shows significant differences in performance between the research groups. Even though, the analysis of the results shows that all the treatments applied were effective, the use of web-based technology resources applied as treatment for groups $\mathbf{3}$ and 2 were more effective than the treatment applied for group 1.
\end{abstract}

Keywords-teacher education; technology integration; web-based technology resources; smart board and inquiry approach.

\section{INTRODUCTION}

Effective use of information and communication technology (ICT) in educational practices has continued to be an issue of concern for stakeholders of the education industry in the world over. Thus, different strategic approaches and policies were adapted in different countries to ensure the integration of ICT in education; yet, hardly are these technology effectively used in the classroom as desired. The reasons advanced for the poor state of ICT integration in education differs over time and from place to place. Lack of ICT facilities was cited more often in early literature as the major factor hindering the use of technology in education. But gradually, lack of ICT facilities in the classroom is becoming no longer an issue at least in many places as more and more technology continue to flow into the schools.

However, despite the provision of ICT and internet facilities in the schools, teachers are still unable to effectively integrate web-based technology resources in their practices [1]. This inability is associated with teachers' low level skills and competence in the use of ICT; making the teacher factor a crucial issue that can undermine the success of ICT integration in schools [2]. Therefore, effective use of ICT in schools lies heavily on how well teachers are prepared for technology integration. Preparing teachers to integrate ICT in their practices need to be rooted deeply and effectively in the teacher education programme from the onset [3]; and teacher educators need to integrate and model the use of ICT in their pedagogical practices as well. However, ensuring effective technology integration in teacher education would require a careful planning and transformational changes in curriculum contents and pedagogical practices in addition to having access to ICT facilities. Even though technology integration in educational practices is 
universally appreciated and considered a welcome development by most educators [4], most of the teacher educators are yet to integrate the use of ICT in their pedagogical practices [5].

Most often, lack of theoretical and conceptual framework is cited as a factor affecting the integration of ICT in teacher education and by teacher educators. In this study, the Technology, Pedagogy and Content Knowledge (TPACK) theory [6] developed as a framework to guide technology integration in teacher education was employed to guide the research design. In line with this theory, a framework for technology integration in Social studies (citizenship) teacher education curriculum for Nigerian Colleges of Education was designed to guide this study on one hand (for curriculum based technology integration). On the other hand, the Giving, Prompting and Making (GPM) model [7] was adapted to guide ICT integration in social studies teacher education pedagogical practices for teacher educators. The design of the study is therefore a practical application of the TPACK theory and the GPM model with particular focus on social studies teacher education within the framework of Nigerian Colleges of Education. Apart from testing the practical application of the TPACK theory and the GPM model, the study is design to determine the effects of web-based technology resource in the use of inquiry approach for citizenship pedagogy in Nigerian teacher education.

\section{LITERATURE REVIEW}

The web is a digital environment accessed through the internet at all time and everywhere on the globe [8]. Web 2.0 is characterised with advanced but user friendly digital technology that permit the use of interactive multimedia [9]. The web environment therefore provides two broad web-based resources useful to but not limited to educational practices: 1) the digital multimedia webbased technology that gives users access to unlimited digital online text, audio, video and audio-visual documents accessed through the use of search engine tools like the 'Google' and others that exist in variety; and, 2) the web-based digital interactive multimedia technology that allows on line interaction between individuals, groups and institutions (such as Facebook and Yahoo messenger) using text, audio, or video conversation as may be preferred by the user. This technology has made it possible for human race to interact irrespective of time and place making distance no longer a barrier for human interaction. This feature of the webbased technology resources has in the recent times influences a lot of innovation and transformation in education and pedagogical practices.

Using the web-based interactive multimedia technology (such as Facebook, blog, twitter, etc.), innovative teachers with good knowledge and skills of ICT usage were able to engage students in web-based problem-solving activities that prompts learners into online inquiry in search of or access to learning content [10]. While being engaged in such learning tasks students most often collaborate with peers in critical discussion and seek to verify their findings with other teachers and professionals online in their attempt to solve problems or issues under investigations [11]. Within the web environment there are quite a number of resources that are used by some educators for feedback and evaluation of content learning from students using web-Quest, online drill-and-practice, online computer based test and quiz in addition to the conventional classroom evaluation process [12].

Such innovative use of the web-based technology resources has provided an unlimited alternative approach to students-centred learning that is inquiry based; an alternative approach that has dual benefits on the students in particular and the learning process in general. Apart from enhancing the students skills in the use of ICT and exposing them to a wide variety of online learning contents [13]; the students were exposed to challenging tasks that can improve their problem-solving skills, collaborative learning and teaching, critical thinking process and reflective reasoning [14], [15]; and, the acquisition of some meaningful social values such as cooperation, patience, tolerance and team work reflecting on the affective domain aspect of lifelong learning. With this development, students no longer rely on teachers as the main source of knowledge [2]. Though, some people consider this development as undermining the value of teachers [2]. Those with such perception need to know that, innovative use of the web-based technology resources in pedagogical practices is only transforming the role of teachers from that of being providers of knowledge to that of being facilitators or co-ordinators of the learning resources [16]. Such a transformation is not in any way undermining the value of teachers who still need to create and structure students learning experiences; 
rather, it should be considered as a shift from teacher to students’ centred learning.

Studies relating to use of web-based technology resources in educational practices differs in focus, objectives and intended goals. Most of the studies were only reporting on the advantages derived from the general educational use of web-based resources. Such studies have provided a great deal of information indicating that, use of the web-based technology resources: facilitates students' attainment of educational goals [8], [11]; increases students self-confidence on issues relating to content learning and ICT skills [13]; expand students conceptual horizon of issues from local to global perspectives; and, facilitates students understanding and appreciation of the diversity of human values and its consequent effect on peoples' perception and thought [13]; enhances students web literacy, searching skills, web reading skills, web evaluation skills, use of appropriate keys to locate web information and understand their limitations and possibilities [15]; attracts students attention and motivates their learning interest as they consider hand-on-technology amazing; thereby, making the learning process a fun [13]. Even though existing studies as cited above reported the usefulness and need for the integration of web-based technology resources in educational practices, not much is done to explore the use of the web-based resources in particular pedagogical designs and subject areas in relation to teacher education and TPACK theory.

Innovative use of the web-based resources by academics in pedagogical practices has led to the emergence of formally recognised e-learning programme by a number of increasing universities and other institutions of higher learning in the world over. This and other ICT related innovation in the education industry has resulted in the emergence of new learning process theories, curriculum integration theories, and new instructional models in all disciplines.

\section{THE THEORETICAL CONSIDERATIONS}

The approaches to technology integration in educational practices predating the surfacing of Technology Pedagogy and Content Knowledge (TPACK) were 'techno-centric' in nature [17]. This approach to technology integration in the learning process is largely influenced by a consideration of the educational technology being used or available as the case may be; "rather than students learning needs relative to curriculum-based content ...”[18:395]. It is an approach where a serious consideration for the 'affordability' and 'constrains' of technologies play the key role in designing and planning technology integration for content-based learning instructions [17] as practiced in schools. The two major curricular components (content and pedagogy) are hardly given any deserving attention; perhaps, just to ensure 'technology' is in the class. This approach is considered as inadequate for effective technology integration in teaching [19].

Technology integration in teacher education is largely influenced by this approach. Pre-service teachers irrespective of their teaching subjects were exposed to the same 'stand-alone' technology courses; on assumption that, the knowledge of technology needed by teachers irrespective of their subject disciplines and the level of their students is same [18]. This approach has no consideration for the differences that exist between subject disciplines in terms of their organisational frameworks; established practices, "ways of acknowledging evidence and proofs, and approaches of developing knowledge” [18]; giving little or no attention to the uniqueness of subject content, process of inquiry and pedagogical approaches peculiar to each discipline. The use of educational technologies in teacher educational practice is therefore not well integrated into curriculum based teaching and learning [20. Thus, little we should wonder why the current practices of technology integration is tilted towards the use of "presentation software, learner friendly websites and management tools to enhance existing practice; while the emphasis should have been on such uses that support inquiry, collaboration and reformed practice” [18:395].

Apart from changing the conventional instructional materials, technology integration in educational practices has some far reaching implications on content learning and pedagogical approaches for classroom instructions. Thus, "technology integration approach that do not reflect disciplinary knowledge differences, and the corresponding processes for developing such knowledge, ultimately are of limited significance, ignoring as they do the full complexity of the dynamic realities of teaching effectively with technology" [18:396]. As such, knowledge of disciplinary factors and instructional approaches intrinsic in each subject discipline are necessary to consider in designing the kind of knowledge needed by teachers' in 
their respective disciplines to teach effectively with technology.

Against this background, the TPACK framework and theoretical underpinnings was conceptualised and developed; establishing new curricular components needed in teachers education for the use of technology in instructional practices. The TPACK framework therefore provides the needed framework guiding the development of knowledge in teacher education that can lead to effective use of technology in subject-based instructions.

\section{Technology, Pedagogy, and Content Knowledge (TPACK)}

The theoretical conceptions leading to the development of TPACK consider teachers' knowledge of technology, pedagogy, subject content; and knowledge of the interplay of the three components as critical for effective use of technology in instructional practices [6]. This conception was developed into becoming the 'Technological Pedagogical Content Knowledge (TPCK)' model; expanding the Shulman's Pedagogical Content knowledge theory to include technology [18]. The TPCK model (now-TPACK), identifies seven types of knowledge needed by teachers to use technology effectively in their pedagogical practices in teaching curriculum content of subject-disciplines. The seven knowledge components arising from the inter-connection and interplay of the three major curricular components are represented in the diagram bellow.

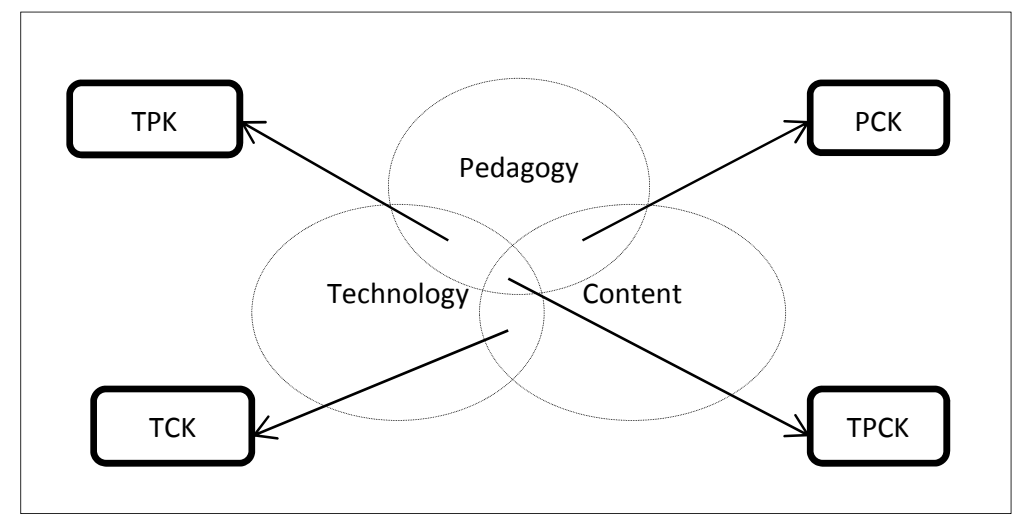

Figure 1.The TPACK Framework

\section{Content Knowledge (CK)}

This is the knowledge of the curriculum contents of a subject discipline. It is important for teachers' to have a good knowledge and understanding of the facts, ideas, concepts, theories, organisational frameworks; as well as, the nature of inquiry and knowledge of evidence and proof of their teaching subject [21]. Inadequate knowledge and understanding of the subject content can be disastrous in classroom instructions; most often, leading to the dissemination of misleading information than can result to misconception and undesired disposition [18], [22].

\section{Pedagogical Knowledge (PK)}

This is an aspect of teacher education that deals with the general knowledge of teaching methods and learning process; and, such knowledge of teaching methods peculiar to subject-disciplines. Four important components make up the pedagogical content knowledge: knowledge of teaching methods; knowledge of the learning process; and, knowledge of the learner. The teacher therefore needs to have a good knowledge and "understanding of social, cognitive, and developmental theories of learning and how they apply to students in classroom” [18:399]; knowledge of instructional designs and approaches, classroom management, lesson plan development and implementation, and knowledge of instructional evaluation [21]; knowledge of the learner; and, knowledge of evaluating students learning. This knowledge "helps the teacher to understand how students construe knowledge and acquire skills in different ways; and how they develop habits of mind and disposition towards learning” [18:399].

Technological Knowledge (TK) 
This is defined this as the knowledge of both standard and advance technology [6]. They described 'standard technology' as the conventional instructional materials used over time in classroom teaching such the black/white board, printed pictures, maps and charts, and text books; while describing 'advanced technology' as digital technology, referring to internet and computer associated technologies that can be used in educational practices. Technological knowledge therefore refers to knowledge of how to operate and use these technologies. However, advanced technology has and would continue to change over time as new technologies continue to emerge [23]. Because of the changing nature of technology in the present information age, the definition of technological knowledge would continue to be dynamic [18].

Earlier, knowledge of digital technology was popularly associated with the concept of 'technology literacy'-knowledge and skills of operating computer associated technology. This alignment has now shifted to a broader concept-ICT literacy; an emerging concept that conceptualises technological knowledge as a knowledge base that hinges on the integration of technology and information literacy with problem-solving. Thus, the meaning of technological knowledge has advanced from technology literacy as earlier conceived to ICT literacy. Therefore, technological knowledge within the context of the TPACK can be re-define to mean a knowledge base that describe teachers ability to use digital technology, communication tools and networks for the purpose of accessing, managing, integrating, evaluating, creating and communicating information; with due consideration of the legalities and ethics governing the use of digital information in the information age.

\section{Pedagogical Content Knowledge (PCK)}

While content knowledge as earlier described deals with the acquisition of facts, skills, ideas, frameworks and theories relating to the knowledge of specific disciplines (school subjects); pedagogical knowledge deals with facts, ideas, frameworks, models and theories relating to teaching strategies, methods and approaches used by teachers for classroom instruction in teaching subject contents. On the other hand, PCK is a knowledge base arising from the interplay of the two knowledge components (PK and $\mathrm{CK}$ ); it therefore deals with an understanding of the intersection of PK and CK and implications of the intersection in teaching learning situations. It is a knowledge base that describes teachers' understanding of how pedagogical designs and subjectcontent intertwined to facilitates the achievement of instructional objectives; it also deals with teachers' ability to apply this knowledge in selecting appropriate pedagogical approaches that can suits and facilitate the classroom delivery of specific learning contents; as well as, the utilisation of this knowledge in re-arranging learning content to suits particular pedagogical designs to facilities the teaching learning process. PCK is a knowledge that deals with "the representation and formulation of concepts, pedagogical techniques, knowledge of what makes concepts difficult or easy to learn, knowledge of students prior knowledge, and theories of epistemology; and knowledge of teaching strategies that incorporate appropriate representation in other to address learners difficulties and misconceptions and foster meaningful understanding” [6:1027].

\section{Technological Pedagogical Knowledge (TPK)}

This knowledge is concern with an understanding of the intersection between technological knowledge and knowledge of pedagogical designs in teaching learning situations; and, how the two intertwine with each other to improve the process of teaching and learning. It is a knowledge base that is concern with teachers understanding of how technological tools facilitate the use of pedagogical designs in teaching subject content; and the ability to apply this understanding in selecting appropriate technologies that can properly fit into particular pedagogical designs for the purpose of promoting students understanding of subject content in classroom teaching.

In particular, TPK has to do with: the knowledge of existing technology and an understanding that, variety of technological tools exist for different educational task; knowledge of the potential usability of the existing technologies in educational practices; knowledge of the advantages and disadvantages of these technologies; knowledge of how to integrate these technologies into teaching styles for classroom instructions [6]. It involves how the process of teaching and learning changes when certain technologies are used; and an "understanding of the constraints and affordance of particular technologies and the educational context within which they function best” [18:340]. The application of this knowledge in educational practices implies that, teachers' need to be 
flexible in their choice and use of technology to suit pedagogical approaches; requiring open-mindedness, creativity and innovation in redirecting the use and application of technology to improve teaching and learning [18].

\section{Technological Content Knowledge (TCK)}

This is the knowledge of how subject content can better be presented using technology. It deals an understanding of how the two (technology and subjectcontent) domains influences one another. It implies teachers' knowledge and ability to manipulate subject using technology to improve students understanding of subject matter in the process of teaching and learning [19]. It is a knowledge base that arises from an understanding of the interplay of the two domains; and the consequent implications of the interplay in the learning process. This knowledge help teachers' to determine which technology can best represent specific subject in teaching and learning [18:395].

\section{DESIGN OF THE STUDY}

The design of this study has two dimensions: curriculum-based technology integration in social studies teacher education curriculum as guided by the TPACK framework; and, technology integration (ICT-based inquiry instruction) in teacher education pedagogical practices as guided by the GPM model. The latter is particularly focus on the utilisation of 'standard technology', the Smart Board and web-based resources in the use of inquiry approach for instructions in social studies teacher education. The conceptual framework of the study is depicted in figure 2 below. 
Figure 2. The research Conceptual Framework

Contrary to the conventional practices in Nigerian teacher education where content, methods and educational technology are taught as separate curriculum components, the three are integrated into a single curricular component in the design of this study. As conceived in the framework, the pre-service teachers (participants) were exposed to learning: social studies-subject content (CK), methodology (PK) and technology (TK) curriculum simultaneously within the framework of a single course curriculum. This integration is conceived for the purpose of this study as 'curriculum-based technology integration' in social studies teacher education curriculum guided by the TPACK framework.

Thus, instead of learning technology as a course of its own without being link to any particular pedagogical design and particular subject area; or learning pedagogical designs (methods) without being link to any particular single subject content and technology as practiced in Nigerian teacher education. This approach of 'curriculumbased technology integrated in teacher education curriculum' provides the pre-service teachers the advantage of learning methodology and technology in 
relation to the teaching subject. As well as seeing the inter-link, the interplay and practical application of the three components in classroom instructions as modelled by teacher educators. The design also provides an enabling environment challenging teacher educators to model the use of technology in their pedagogy. Thus, helping pre-service teachers to practically learn the application of the three dimensional components in an instruction. The design of this framework is in line Shulman's and TPACK theoretical perspectives.

The second aspect of the research design involves technology integration in teacher education pedagogical practices in line with the GPM instructional model. This aspect of the study focuses on the use of technology in teacher education instructions. In line with the framework and model, the inquiry method integrated with use of web-based resources, interactive smart board and power point is used for the classroom instructions. The framework of the study is design to measure the effect of 'curriculum-based technology integration' and use of web-based technology resources and smart board in 'ICTbased inquiry instruction' on pre-service teachers' achievement in learning social studies subject content; methods; technology; and application in teaching. The ICT-based classroom inquiry instruction is guided by the GPM model.

\section{AN OVERVIEW OF THE INTERVENTION CONDITION}

Three intervention designs were used in this study and each intervention design was administered to a research group. Therefore three groups were involved in the study. All the three groups were exposed to the inquiry approach using the GPM model. However, group 1 were taught social studies, methods, and technology as separate curriculum components while group 2 and 3 were exposed to technology integrated curriculum where the three curricular components were integrated into a single course design. The learning content of the three domains were selected from the 2008 approved NCE (National Certificate in Education) curriculum.

For classroom instructions, group 1 was exposed to inquiry based instruction in line with the GPM model to learn social studies, methods, and technology as separate courses coded as SOS 211, EDU 211 and EDU 212 respectively. Standard technology (white board, printed maps, charts and text book) were integrated into the inquiry process at different stages of the teaching learning process. While group 2 were exposed to learning the integrated curriculum using the inquiry based instruction in line the GPM model. The use of web-based technology resources and power point was integrated in the pedagogical instructional design. Group 3 on the other hand were exposed to learning the integrated curriculum using inquiry based approach in line with the GPM model; the use of interactive smart board and web-based technology resources was integrated into the pedagogical instructional designs of the teaching-learning process. The pedagogical approaches adopted for each group is presented in figure 3, 4, and 5.

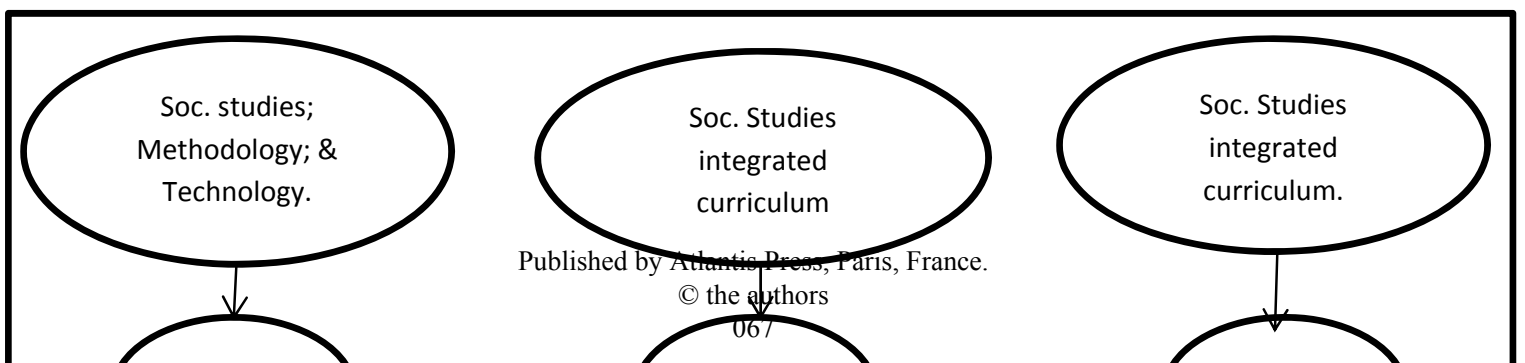


In line with the GPM model, the inquiry learning process for all the groups started with the 'Giving' stage. This is the stage where the teacher educator skilfully introduces the problem, a situation, an issue or the phenomenon to be investigated from the learning content. Depending on the choice of the facilitator; questioning technique, short-story line approach or short lecture are all appropriate approaches that can be used at this stage. In utilising any of the approaches for the giving stage, the facilitator must bear mind that, his responsibility at this stage is to guide the learners towards having an over view of the nature and scope of the issues or problem that is being introduced to the class for inquiry. The facilitator must therefore be able to provoke students' curiosity and thought; and arouse their interest. At the end of this stage, the learners' attention must have been drawn towards seeing the need for further exploration of the issue being presented.
Guided by these considerations, all the inquiry instructional sessions for all the groups started with this stage. Each group was exposed to thought-provoking presentations, story lines and questioning; therefore, attracting their interest and curiosity over issues being presented. Such an approach was adopted to engage the learners into critical reasoning that lead students to raise a number of questions that need to be explored further; therefore building the inquiry foundation. For group 1 as indicated in figure 3 above, the teacher educator uses the conventional white board to support his pedagogical approach for the giving stage while engaging the preservice teachers in the inquiry process for the three domains as separate courses. For group 2, the teacher educator uses the power point to support his pedagogical approach for the giving stage; while group 3 uses the smart board technology. After this stage, the inquiry process advanced to the next stage 'Prompting' presented in figure 4 below.

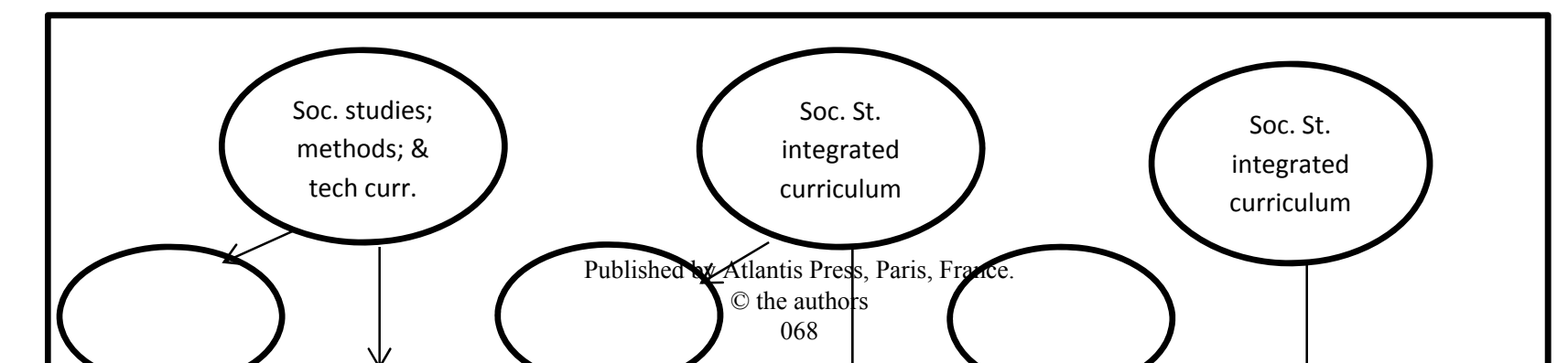




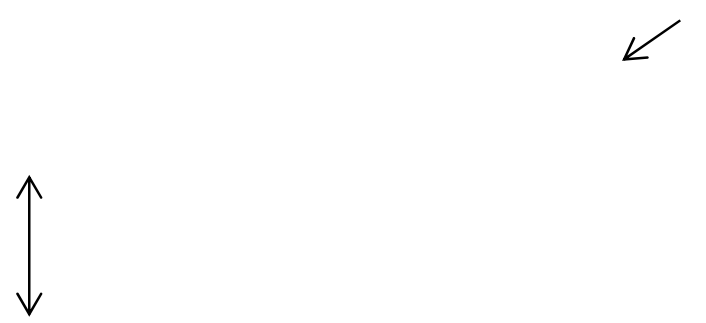

Figure 4. The Prompting Stage of the GPM model [7]

The prompting stage requires longer time; it is the stage where the learners start their preliminary exploration of facts, theories and conceptual explanations to gain deeper understanding of the issue under investigation. The learners' exploration at this stage was also directed towards understanding the current state of the issue they are investigating; the possible different interpretations surrounding the issue; and, the possible multi-dimensional nature of the study. After gaining deeper understanding of the issue, the learners try to define the issue within the context of their understanding; establishing the scope of their investigation; re-define and shape the earlier questions that comes to their mind during the giving stage into well-define inquiring questions; map out their plan of actions and share responsibility; set out their objectives for each responsibility given that would collectively lead to achieving their overall group objectives and goals.

Unlike the giving stage that is relatively teachercentred, the prompting stage was more interactive and student activity oriented in nature; it involves team work, collaboration, planning, decision-making and responsibility. The learners become socially engaged with one another in the learning process that was directed toward problem-solving, creating awareness, or construing knowledge that can explain situations or cause and effect relationships. The learners have to be involved in a number of interactions starting with: direct learner content interaction; teacher-mediated content-learner interaction; and, learner to learner interactions.

'Making' is the last stage of the inquiry process using the GPM model. Three steps are involved in the making stage; starting first with the consideration of literature explored and analysis of data the pre-service collected during the prompting stage to establish findings that can lead toward:

a. Explaining or providing a better description of situations, a phenomenon or problem situation based on facts, evidence and theories; or

b. Providing solutions to issues and problems under investigations; or

c. Producing a product (useful in addressing issues) under investigations.

Presentation of findings for consideration and discussion to the class as a whole by each cluster group is the second step of the stage. The third step (after the class discussion) is the step that has to do decision making on: what to do the findings; the recommendations to give or action to be taken where applicable; and the solution to provide in 
solving the problem in focus. Three things are of interest to the researcher at this stage that includes the following;

a. Observing what technological tools the preservice teachers choose to engage themselves with at this stage; and b. Observing the participation/contribution and the display of critical thinking/reasoning of the preservice teachers as they discuss their findings.

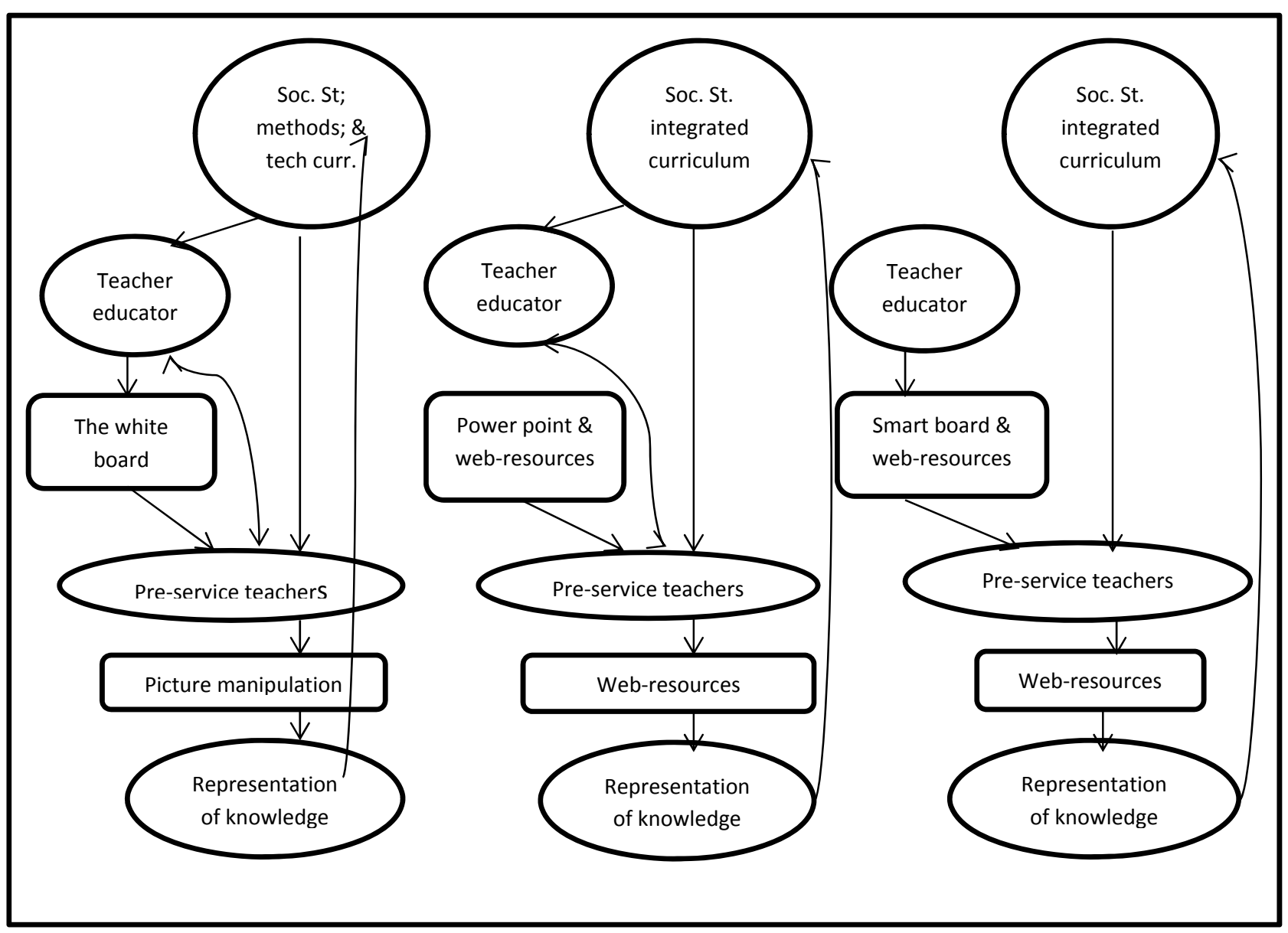

Figure 5. The Making stage of the GPM model [7]

The pre-service teachers in group one choose to use only the printed materials (printed pictures and charts) and the white board in doing and presenting their work as shown in figure 4.4 above. They use the printed materials in accessing content to understand the issues under investigation; and in gathering data for analysis in relation to the inquiry questions earlier raised at the giving and prompting stage. They also use the data resources from printed materials in learning about the inquiry learning process, information gathering techniques for literature review and data analysis to arrive at a finding. In presenting their work for discussion to the class, they use printed chart, picture manipulation and the white board to support their presentation; they choose to use the print media in communicating the knowledge they have generated from the inquiry process.

Group 2 and 3 on the other hand use the web in accessing information to understand the issues under investigation; in learning about the inquiry teachinglearning process; in learning about data gathering techniques; literature review and data analysis. The literatures reviewed by the two groups were sourced from electronic data base(s) using the web. Group two uses the 
Power Point effectively and skilfully in presenting their work and finding to the class for discussion while group three uses the Smart Board. The two groups choose to use variety of digital social networking tools available on the web in communicating the knowledge they have generated as a means of getting feedback. The groups intend to consider meaningful contributions, suggestions and criticism from the feedbacks to improve on their work and if possible send it for publication where suitable.

\section{METHODOLOGY}

Quasi-experiment design involving three groups was employed for this study. The sample population for the study totalling forty five (45) are social studies pre-service teachers (males and females) selected using the purposeful sampling technique. The sample population were randomly assigned to the three research groups; fifteen participants in each group. The first group ware exposed to the conventional teacher education curriculum and pedagogical practices. The group members were taught social studies (citizenship education) curriculum, methods curriculum (the inquiry approach), and educational technology (ICT) curriculum as separate curriculum components. The second and third group on the other hand, were exposed to the 'social studies technology integrated curriculum' that is: citizenship curriculum (social studies) integrated with methodology curriculum (the inquiry method); and technology curriculum (ICT).

The first group were exposed to the conventional teacher education pedagogical practices using the inquiry method and standard technology as instructional materials; while the second and third groups were exposed to the 'ICT-based instruction' integrating the use of web-based resources, smart board and power point in the inquiry approach. The integration of these technologies in the pedagogical practices as used for the research groups is illustrated in the instructional model above (figure 2, 3 and 4 respectively). Post-test was administered to the groups to measure their achievement on learning subject curriculum (Soc. Studies/citizenship), methods curriculum (pedagogical approaches) and technology curriculum (ICT), application in class teaching, and in the overall achievement test.

Two instruments were used for the achievement test (as the post-test): the end of semester written exams (60 marks); and, micro-teaching practice exercise (40 marks). The written exam is a two and half hour essay test in which the pre-service teachers answered three essay questions (one from each section). Six questions were provided: two questions $(1 \& 2)$ in section A (to measure Subject-content knowledge); questions 3 \& 4 in section B (to measure knowledge of Methodology); and questions 5 \& 6 in section C (to measure knowledge Technology). The rating of performance on each question is ranging from 1-20 marks. The micro-teaching exercise on the other hand measures the pre-service teachers' skills in the application of the integrated knowledge of content, technology and pedagogy in classroom teaching. Performance in the micro-teaching ranges from 1-40 marks: Lesson plan development (1-4 marks); Selection of appropriate instructional technology for giving (1-4 marks); Effective use of giving skills (1-4 marks); Skills and effective use of the selected instructional technology in the giving stage of the inquiry process (1-4 marks); Selection of appropriate instructional technology for prompting (1-4 marks); Effective use of prompting skills (1-4 marks); Skills and effective use of the selected instructional technology in the prompting stage of the inquiry process (1-4 marks); Skills of handling students' use of appropriate technology in the making stage (1-4 marks); Effective classroom management in the making (1-4 marks); Skills of handling students' findings (1-4 marks). The rating scores of the two instruments: written exam (60 marks) and micro-teaching exercise (40 marks) has a total of 100 marks as the overall achievement test scores.

The data collected from each of the research groups were recorded in the format provided in the sample below. Data of the three groups were analysed using the SPSS software.

Table 1. Sample Scores of the Achievement test 


\begin{tabular}{clcccc}
\hline Candidates & $\begin{array}{l}\text { Subject } \\
\text { content } \\
\text { 20 } \\
\text { marks }\end{array}$ & $\begin{array}{l}\text { Methodology } \\
\text { 20 marks }\end{array}$ & $\begin{array}{l}\text { Technology } \\
\text { 20 marks }\end{array}$ & $\begin{array}{l}\text { Application } \\
\text { in teaching } \\
\text { 40 marks }\end{array}$ & $\begin{array}{l}\text { Total } \\
\text { marks }\end{array}$ \\
\hline $\mathbf{1}$ & 12 & 10 & 08 & 20 & 50 \\
$\mathbf{2}$ & 16 & 10 & 09 & 22 & 57 \\
$\mathbf{3}$ & 14 & 13 & 09 & 24 & 60 \\
$\mathbf{4}$ & 13 & 11 & 07 & 21 & 52 \\
$\mathbf{5}$ & 11 & 11 & 10 & 20 & 52 \\
\hline
\end{tabular}

One independent (grouping) variable (the curriculum based ICT integration and ICT based instruction) as the factor with three levels (three intervention designs/groups) was used in the design of the study. Therefore, one-way analysis of variance (ANOVA) was used in analysing the data to find out if any significant differences exist between the three research groups in their mean score achievement on: subject content, methodology, application in teaching, and in the overall total achievement test scores. The differences between the groups was further investigated using Pos-hoc (Tukey
HSD) analysis to find out the degree of differences between the groups; and, to determine which of the treatments/intervention has a significant impact on the pre-service teachers' achievement in content learning, methodology, technology, application in teaching, and the overall total achievement.

\section{RESULTS}

The assumption for homogeneity of variances was tested using the Levene's test of homogeneity. Result of the Levene's test analysis is presented in table 1 below.

Table 2: The Levene’s Test of Homogeneity of Variances

Test of Homogeneity of Variances

\begin{tabular}{lcccc}
\hline \hline & Levene Statistic & df1 & df2 & Sig. \\
\hline Social studies Subject & 1.056 & 2 & 42 & .357 \\
content & & & & \\
Methodology & 1.541 & 2 & 42 & .226 \\
Technology & 4.276 & 2 & 42 & .080 \\
Application in Teaching & 2.231 & 2 & 42 & .120 \\
Total Achievement Scores & .633 & 2 & 42 & .536 \\
\hline \hline
\end{tabular}

All the Sig. values indicated in the Levene's statistics table above were greater than .05, (therefore, not significant); indicating that, the assumption of homogeneity of variances was not violated. The result of the analysis of variance (ANOVA) is presented in table 2 below; indicating significant differences between the three intervention groups in their mean score achievement on: Subject content, Methodology, Technology, Application in Teaching, and the overall total achievement scores.

Table 3. The Analysis of Variance

ANOVA 


\begin{tabular}{|c|c|c|c|c|c|c|}
\hline & & Sum of Squares & $\overline{\mathrm{Df}}$ & Mean Square & $\bar{F}$ & Sig. \\
\hline \multicolumn{2}{|c|}{ Social studies Subject content Between Groups } & 128.133 & 2 & 64.067 & 93.865 & .000 \\
\hline & Within Groups & 28.667 & 42 & .683 & & \\
\hline & Total & 156.800 & 44 & & & \\
\hline \multirow[t]{3}{*}{ Methodology } & Between Groups & 227.511 & 2 & 113.756 & 185.663 & .000 \\
\hline & Within Groups & 25.733 & 42 & 613 & & \\
\hline & Total & 253.244 & 44 & & & \\
\hline \multirow[t]{3}{*}{ Technology } & Between Groups & 206.711 & 2 & 103.356 & 219.980 & .000 \\
\hline & Within Groups & 19.733 & 42 & .470 & & \\
\hline & Total & 226.444 & 44 & & & \\
\hline \multirow[t]{3}{*}{ Application in Teaching } & Between Groups & 257.378 & 2 & 128.689 & 355.588 & .000 \\
\hline & Within Groups & 15.200 & 42 & .362 & & \\
\hline & Total & 272.578 & 44 & & & \\
\hline \multirow[t]{3}{*}{ Total Achievement Scores } & Between Groups & 1348.578 & 2 & 674.289 & 217.847 & .000 \\
\hline & Within Groups & 130.000 & 42 & 3.095 & & \\
\hline & Total & 1478.578 & 44 & & & \\
\hline
\end{tabular}

The significant differences in the mean achievement score of the groups indicated above were further investigated by the analysis of multiple comparisons using the Post-hoc (HSD) test. The Post-hoc analysis was conducted to determine where exactly the significant differences exist in each pair of the groups for their achievement in subject content, methodology, technology, application in teaching, and the overall achievement test scores. Findings from the Post-hoc analysis of multiple comparisons of the pre-service teachers' achievement in social studies subject content shows that, there was significant difference between group 1 and 2 compared indicating a Sig. value of $.000<.05$ (significant) and a mean difference value of $4.133^{*}$ (significant); and between group 1 and 3 compared indicating a Sig. value of $.000<.05$ (significant) and a mean difference value of 2.067* (significant). The differences in achievement between groups 2 and 1, and between groups 2 and 3 compared was also significant; indicating a Sig. value $.000<.05$ (significant) for each pair and a significant mean difference of $-4.87 *$ and $-2.067 *$ respectively. There was also significant differences in the mean score achievement of group 3 with groups 1 and 2 compared; indicating a Sig. value of $.000<.05$ (significant) for each of the pair and significant mean difference value of $2.067 *$ and $2.067 *$ respectively.

The Post-hoc analysis of multi comparisons for the pre-service teachers' achievement in methodology (knowledge of pedagogical approaches) shows that, there was significant difference in achievement between group
1 and 2 and between groups 1 and 3 compared; indicating a Sig. value of $.000<.05$ (significant) for each pair and a significant mean difference value of $-4.667^{*}$ and $-4.867^{*}$. The result also indicates a significant difference between group 2 and 1 compared with Sig. value of $.000<.05$ (significant) and a significant mean difference of $4.667^{*}$. The differences between groups 3 and 1 was also significant, indicating a Sig. value of .000<05 (significant) and a significant mean difference value of $4.867 *$.

The differences in the mean score achievement of the pre-service teachers' in learning the use of technology was significant between group 1 and 2 and between group 1 and 3 compared; indicating a Sig. value of .000<.05 (significant) for each pair and a significant mean difference value of $-4.333^{*}$ and $-4.733^{*}$ respectively. Significant differences were also noticed between group 2 and 1 and between group 3 and 1 compared; indicating a Sig. value of $.000<.05$ (significant) for each of the pair and significant mean difference values of $4.333^{*}$ and 4.733* respectively.

The pre-service teachers' achievement scores in the ability to apply the integrated knowledge of subject content, methodology and technology in classroom teaching significantly differs between group 1 and 2 and between group 1 and 3 compared. The two comparisons indicated a Sig. value of $.000<.05$ (significant) for each pair and significant mean difference value of $-4.667^{*}$ and $-5.400 *$ respectively. There was also significant differences between group 2 and 1 and between group 2 
and 3 compared; showing a Sig. value of .000>.05 and .005 (significant), and significant mean difference value of $4.667^{*}$ and $.733^{*}$ for each of the pairs respectively. Significant differences between group 3 and 1 and between group 3 and 2 was also indicated; showing a Sig. value of $.000<.05$ (significant) for each pair of comparison and significant mean difference value of 5.400* and .733* respectively.

In the overall achievement test scores, the differences between groups 1 and 2; groups 1 and 3; groups 2 and 1; groups 2 and 3; groups 3 and 1; and between groups 3 and 2 compared were all significant. A Sig. value of .000<.05 (significant) was indicated for each pair of the comparison; and significant mean difference value of -9.533*; 12.933*; 9.533*; 3.400*; 12.933; 3.400* were also indicated for each pair of comparison respectively.

However, the pre-service teachers' achievement in learning pedagogical approaches (methodology) between group 2 and 3 and between group 3 and 2 compared was not significant. The comparison for the two pairs indicated a Sig. value of .765>.05 (not significant), and in-significant mean difference value of .200 against each of the pairs compared. The differences in the pre-service teachers' achievement in learning to use technology (ICT) in teaching between group 2 and 3 and between group 3 and 2 were not significant as well. Result of the multiple comparisons for the two set of pairs indicated a Sig. value of .258>.05 (not significant) each and a mean difference value of .400 each.

The result of the one-way between-groups analysis of variance was conducted to test the effect of curriculumbased ICT integration and ICT based instruction (the intervention) on pre-service teachers' (participants) achievement in learning: social studies subject content, methodology, technology, application in classroom teaching, and the overall achievement test scores; as measured by the NCCE end of semester exams and micro teaching scale. The participants (45 pre-service teachers') were divided into the three different intervention groups accordingly. The result of the analysis shows that:

a. There was a statistically significant difference at $p<.05$ level of significance in the achievement scores of the three groups for social studies subject content knowledge $[F(2,42)=93.8$, $p=.00]$. The actual difference in the mean scores between the groups was large. The effect size, calculated using eta squared was .82. Post-hoc comparison using the Tukey HSD test indicated that, the mean score of group $1 \quad(M=21.67$, $S D=.900)$ was significantly different from group $2(M=17.53, S D=.915)$ and group $3(M=19.60$, $S D=.163)$.

b. There was significant difference in the preservice teachers' achievement scores on methodology between the three intervention groups at $p<.05$ level of significance, $[F(2$, $4)=185.663, P=.00]$. The actual difference in the mean scores between the groups was large. The effect size, calculated using eta squared was .10. Post-hoc comparison using the Tukey HSD test indicated that, the mean score of group 1 $(M=17.33, S D=.159)$ significantly differ from group $3(M=22.20, \quad S D=.862)$; but, the differences between group $2(M=22.00, S D=.845$ and 3 was not significant statistically.

c. There was significant difference in the preservice teachers' achievement scores for technology between the three intervention groups at $p=.05$ level of significance, $[F(2,4)=219.980$, $p=.00]$. The actual difference in the mean scores between the groups was large. The effect size, calculated using eta squared was .91. Post-hoc comparison using the Tukey HSD test indicated that, the mean score of group $1 \quad(M=17.87$, $S D=.516)$ and group $3(M=22.60, S D=.507)$. The mean score difference between group 2 $(M=22.00, S D=.914)$ and 3 was not significant.

d. There was significant difference in the preservice teachers' achievement scores for application of TPCK in classroom teaching at $p<.05$ level of significance, $[F(2,4)=128.689$, $p=.00]$. The actual difference in the mean scores between the groups was large. The effect size, calculated using eta squared was .94. Post-hoc comparison using the Tukey HSD test indicated that, the mean score of group $1 \quad(M=17.27$, $S D=.118$ ) was significantly different from group $2(M=21.93, S D=.206)$ and group $3(M=22.67$, $S D=.371)$.

e. There was significant difference in the preservice teachers' overall total achievement scores between the three intervention groups at $p=.05$ level of significance, $[F(2,4)=217.847, p=.00]$. The actual difference in the mean scores between the groups was large. The effect size, calculated 
using eta squared was .91. Post-hoc comparison using the Tukey HSD test indicated that, the mean score of group $1(M=74.13, S D=.413)$ differ significantly from group $2(M=83.64$, $S D=.540)$ and $3(M=87.07, S D=.396)$.

\section{FINDINGS AND DISCUSSION}

Findings from the above analysis showed that, group 1 and 3 has the highest mean score achievement (21.67 and 19.60) respectively in learning social studies (citizenship) subject content. While group 2 has the least mean score achievement (17.53) which was below the mean average value score of 19.06. Meaning that, the intervention designs administered to groups 1 and 3 were more effective than the intervention design administered to group 2 in learning subject content. This finding implies that;

a. using the GPM model in line with the TPACK framework in teacher education pedagogical practices as applicable to intervention 1 and 3 were effective in facilitating social studies preservice teachers' achievement in learning subject content.

b. The use of standard technology as applicable to group 1 and the use of advanced technologyPower Point Slides, Smart Board and Web-based resources (ICT-based instruction) as applicable to group 3 were all effective in improving social studies pre-service teachers' achievement in learning subject content.

c. Integrating technology (standard or digital) to teach subject content, methodology and technology curriculum either as separate curriculum components (as used in intervention 1); or integrated into a single curriculum design (as applicable in intervention 3) were both effective in enhancing social studies pre-service teachers’ achievement in learning subject content.

In learning methodology, the findings of this study indicated that group 3 and 2 were having the higher mean score 22.20 and 22.00 respectively for achievement in learning methodology. While group 1 has the least mean score achievement (17.33), lower than the average mean score value (20.51). This implied that, intervention 3 and 2 were more effective, having a mean score achievement that was above the average mean score value each. Meaning that, social studies pre-service teachers' achievement in learning pedagogical designs and approaches would be better; if they learn the three curriculum components together in a single curricular design (as used in intervention 3 and 2) than learning methodology as a single curricular component (as used in intervention 1). Pre-service teachers' would learn pedagogical designs better, if teacher educators integrate advanced or digital technology (Power Point, Smart Board and web-based resources) in their pedagogical practices; compared to the use of traditional standard technology as applied in intervention 1 .

The mean score achievement of group 3 (22.60) and group 2 (22.20) in learning the use and application of technology in pedagogical practices were significantly higher than the mean score achievement of group 1 (17.33) that was even below the average mean score value of 20.89. Meaning that, group 3 and 2 intervention designs were effective on pre-service teachers' achievement in learning the use and application of technology in social studies pedagogical practice; while intervention 1 was less effective. This finding implies that, pre-service teachers' would learn the use and application of technology better; if the three curriculum components (subject content, methodology and technology) are integrated and taught as a single curricular design compared to learning the three as separate curriculum components. The finding also implied that, pre-service teachers' achievement in learning the use and application of technology would be higher; if teacher educators integrate digital or advanced technology in their pedagogical practices as used in intervention 3 and 2 compared to the use or integration of standard technology as used in intervention 1.

The pre-service teachers' exposed to intervention 3 and 2 performed better with a mean score achievement of 22.67 and 21.93 respectively compared to group 1 with a mean score achievement of 17.27) in the practical application of subject, technology and pedagogical knowledge (TPCK) in classroom teaching. The mean score achievement of group 3 and 2 was significantly higher than the average mean score value (20.62) while the mean score achievement of group 1 falls much lower than the average mean score; meaning that, intervention 3 and 2 were effective while intervention 1 was less effective on the pre-service teachers achievement in the practical application of TPCK. The implication of this finding is that: 
a. The pre-service teachers' can apply TCPK better in classroom teaching, if the three curricular components are integrated into a single curricular component during the pre-service teacher training.

b. Pre-service teachers' achievement in classroom application of TPCK would be improved if teacher educators integrate and model the use of digital or advanced technology in their pedagogical practices.

Lastly, finding from the study also indicated that, intervention 3 and 2 were effective in the pre-service teachers' overall total achievement (in subject-contentCK, pedagogy-PK, technology-TK, and applicationTPCK combined). Group 3 and 2 that were exposed to intervention 3 and 2 have the highest mean score achievement (87.07 and 83.67 respectively) while group 1 exposed to intervention 1 has the least mean score achievement (74.13), below the average mean score value (81.62). Meaning that, intervention 1 was less effective. By implication, it means that:

a. curriculum based technology integration where the curriculum of subject-content, methodology and technology are integrated into a single curricular design in social studies teacher education can help to improve pre-service knowledge, skills and competence in the application of TPCK in their classroom when in service; compared to the traditional approach where the three are taught as separate curricular components.

b. Integrating digital technology in social studies teacher education pedagogical practices by teacher educators can improve pre-service teachers' achievement in learning subject-content, pedagogy, technology, and their application in classroom practice; compared to the use of traditional standard technology.

c. The GPM model in line with the TPACK theory provide a suitable framework for technology integration in social studies teacher education pedagogical practices that has positive effects on pre-service teachers achievement in the overall teacher training process.

\section{CONCLUSION}

The issue of technology integration in educational practices is still a challenging task for most teachers, particularly in developing countries. Overcoming this challenge is to a large extent dependent on teacher preparation and teacher educators. Thus, even though the traditional practices in teacher education curriculum and pedagogical practices has been fruitful over ages, an effective integration of technology in teacher education (curriculum and pedagogical practices) in line with the TPACK framework would be more fruitful in preparing teachers for the challenge of technology integration in schools. Teacher educators need to consider the use of web-based technology resources in their pedagogical practices, particularly, when utilising the inquiry approach in social studies teacher education instruction. In addition to the findings of this study, such utilisation of the webbased technology in pedagogical practices as established in literature facilitates students learning and achievement.

\section{REFERENCES}

[1] N. P. Ololube, “Teachers' instructional materials utilisation competencies in secondary schools in Sub-saharan Africa: professional and non-professional teachers' perspectives," Proceedings of the $6^{\text {th }}$ International Educational Technology Conference, Emu, North Cyrus, April, 2006.

[2] M. Rosnaini and A. I. Mohammed, "Impact of training and experience in using ICT in in-service teachers basic ICT literacy," Malaysian Journal of Educational Technology, vol. 10, No. 2, pp. 5-10, 2010

[3] T. Teo, "Pre-service attitudes towards computer use: a Singapore survey,” Australian Journal of Educational Technology, vol. 24, No. 4, pp. 413-424, 2008

[4] E. C. Ong, The Effectiveness of Computer Assisted Instruction in Learning Science. Utara Malaysia, Universiti Utara Malaysia (UTM), 1999 [Masters’ Thesis, 1999]

[5] M. A. Yusuf, "Information and Communication Technology (ICT) and education: analysing the National Policy on Education,” International Education Journal, vol. 6, pp. 316-321, 2005

[6] P. Mishrah and M. Koehler, "Technological pedagogical content knowledge: a framework for teachers knowledge," Journal of Teachers' College Records, vol. 108, No. 6, pp. 10171054, 2006

[7] T. C. Hammond and M. M. Manfra, "Giving, prompting, making: aligning technology and pedagogy within TPACK for Social Studies instructions,” Journal of Contemporary Issues in 
Technology and Teacher Education, vol. 9, No. 2, pp. 160-185, 2009

[8] S. S. Liaw, "Consideration for developing constructivist web-based learning,” International Journal of Instructional Media, vol. 31, No. 3, pp. 309-321, 2004

[9] C. Bravo, M. A. Redendo, M. Ortega and M. F. Verdejo, "Collaborative learning environment for the learning of design: a model and case study in Domotics," Journal of Computers and Education, vol. 46, No. 2, pp. 152-173, 2006

[10] M.C. Kim, M. J. Hannafin and L. A. Bryan, “Technology enhanced-inquiry tools in science education: an emerging pedagogical framework for classroom practice,” Journal of Science Education, vol. 91, No. 6, pp. 1010-130, 2007

[11] S. S. Liaw, G. D. Chen and H. M. Huang, "Users attitudes towards web-based collaborative learning system for knowledge management," Journal of Computers and Education, vol. 50, No. 3, pp. 950-961, 2008

[12] A. K. Aggarwal and R. Bento, Web-based Learning and Teaching Technologies: Opportunities and Challenges. London, Idea Group Publishing, 2010

[13] H. Hsiao, C. Chuang, T. Huang and C. Wu, "Web-based collaborative learning in secondary education: teachers reflections,” International Journal of Cyber Society and Education, vol. 3. No. 1, pp. 15-36, 2010

[14] S. H. Jang, "Exploration of secondary students creativity by internet web-based technology into an innovative science curriculum,” Journal of Computers and Education, vol. 52, No. 1, pp. 247-255, 2009

[15] E. Kuiper, M. Volman and J. Terwel, "Developing web literacy in collaborative inquiry activities," Journal of Computers and education, vol. 52, No. 3, pp. 668-680, 2009

[16] R. Heinich, M.Molenda, J. D. Russell and S. E. Smildino, Instructional Media and Technology for Learning, $3^{\text {rd }}$ ed., Ohio, Merrill Prentice Hall, 2002

[17] S. Papert, "A critique of technocentrism in thinking about the school of the future,” Retrieved on $11^{\text {th }}$ November, 2012 from http://www.papert.org/article/ACritiqueofTechnocentrism.html website: 1987

[18] J. Harris, P. Mishra and M. Koehler, “Teachers’ pedagogical content knowledge and learning activity types: curriculum based technology integration reframed,” Journal of Research on Technology Education, vol. 41, No. 4, pp. 393-416, 2009
[19] M. J. Koehler and P. Mishra, “Teachers’ learning technology by design, Journal of Computing in Teacher Education, vol. 21, No. 3, pp. 94-102, 2005

[20] L. Cuban, H. Kirkpatrick and C. Peck, "High access and low use of technologies in high school classrooms: explaining an apparent paradox," American Educational Research Journal, vol. 38, No. 4, pp. 813-834, 2001

[21] L.S. Shulman, “Those who understand: knowledge growth in teaching,” Educational Researcher, vol. 15. No. 2, pp.4-14, 1986

[22] H. Pfundt, and R. Duit, Bibliography: Students Alternative Frameworks and Science Education (5th ed.). Kiel, Germany, University of Kiel, 2000

[23] I. N. Umar and S. Maswan, "The effect of web-based guided inquiry approach on students' achievements,” Journal of Computers, vol. 2, No. 5, pp. 38-43 